\title{
Comparison of retinal breaks observed during 23 gauge transconjunctival vitrectomy versus conventional 20 gauge surgery for proliferative diabetic retinopathy
}

\author{
This article was published in the following Dove Press journal: \\ Clinical Ophthalmology \\ 20 January 2011 \\ Number of times this article has been viewed
}

\author{
Sharif A Issa \\ Alan Connor \\ Maged Habib \\ David HW Steel \\ Department of Ophthalmology, \\ Sunderland Eye Infirmary, \\ Sunderland, UK
}

\begin{abstract}
Background: To assess the rate and type of retinal break formation in patients undergoing 23 gauge transconjunctival vitrectomy surgery for complications of proliferative diabetic retinopathy compared with 20 gauge vitrectomy surgery.

Methods: Retrospective case notes review of two consecutive series of patients who had primary pars plana vitrectomy for complications of proliferative diabetic retinopathy by a single surgeon. The control group had standard 20 gauge vitrectomy surgery whilst the second group had 23 gauge transconjunctival vitrectomy surgery.

Results: Eighty-five eyes were included in the 20 gauge group and 85 eyes in the 23 gauge group. The groups were well matched for surgical complexity and indications for surgery, as well as a variety of other preoperative variables. There was a significant reduction in the incidence of peripheral sclerotomy-related retinal breaks and lesions suspicious for breaks $(4 / 85$ [5\%] 23 gauge versus 14/85 [16\%] 20 gauge, $P=0.02)$ and posterior retinal breaks $(3 / 85$ [4\%] 23 gauge versus $12 / 85$ [14\%] 20 gauge, $P=0.03)$. Six eyes $(7 \%)$ in total had definite new retinal breaks of any type detected in the 23 gauge group compared with $16(18.8 \%)$ in the 20 gauge group $(P=0.04)$. One patient in each group experienced a retinal detachment postoperatively related in both cases to a posterior retinal break associated with recurrent traction.

Conclusion: In this series of patients, 23 gauge transconjunctival vitrectomy surgery was associated with a lower rate of retinal break formation than 20 gauge vitrectomy for proliferative diabetic retinopathy.
\end{abstract}

Keywords: proliferative, diabetic retinopathy, transconjunctival, vitrectomy

\section{Introduction}

Vitrectomy is a proven and effective treatment for the complications of proliferative diabetic retinopathy (PDR). However, rhegmatogenous retinal detachment after vitrectomy for PDR secondary to iatrogenic retinal breaks remains a serious problem, with reported rates ranging from $3 \%$ to $18 \%{ }^{1,2}$ Iatrogenic breaks have been shown to be commoner after vitrectomy for PDR compared with other indications ${ }^{3}$ and related strongly to the complexity of the case, with rates ranging from $12 \%$ for cases with simple vitreous hemorrhage to $78 \%$ with complex fibrovascular proliferations. ${ }^{4}$

Breaks observed can be divided into two groups, ie, posterior breaks related to the dissection of vitreoretinal adhesions, and peripheral breaks which can in turn be subdivided into those related to the sclerotomy sites and those away from the entry sites and related to separation of the vitreous from the retinal surface.
Correspondence: Sharif A Issa Department of Ophthalmology, Sunderland Eye Infirmary, Queen Alexandra Road, Sunderland, SR2 9HP, UK

Tel +44 I9I 2736878

Fax +44 I9I 5140220

Email sharifissa@yahoo.co.uk 
Small incision transconjunctival vitrectomy (TSV) with cannulated sclerotomies has become increasingly popular, with a number of proposed advantages, including reduced postoperative discomfort and more rapid visual rehabilitation. However, concerns have been raised with regard to the occurrence of postoperative hypotony and endophthalmitis, and it has also been questioned whether narrow gauge surgery is associated with an increased rate of peripheral retinal break formation in macular surgery and a lower success rate in retinal reattachment surgery compared with 20 gauge surgery. ${ }^{5,6}$

These concerns are particularly relevant to vitreous surgery for PDR where retinal break formation is more common. Furthermore, the angulated scissors commonly used in conventional 20 gauge vitrectomy surgery cannot be used during narrow gauge surgery, and a change in delamination technique is required to achieve membrane removal. With any new technique it is important to evaluate any potential adverse effects. Therefore, the aim of this study was to evaluate the rate and nature of retinal breaks found during a consecutive series of patients treated with 23 gauge TSV surgery with PDR, and compare them with a similar series of patients treated by the same surgeon with 20 gauge surgery.

\section{Methods}

A consecutive series of patients who had undergone primary pars plana vitrectomy for the complications of proliferative diabetic retinopathy by one surgeon at Sunderland Eye Infirmary from July 2003 to January 2010 were prospectively identified. The cases were divided into two groups, ie, a control group treated from July 2003 to March 2006 where only conventional 20 gauge vitrectomy surgery was carried out, and a second group from July 2007 to January 2010 where only 23 gauge TSV surgery was carried out.

Patients who had vitrectomy surgery between April 2006 and June 2007 were excluded because at that time the surgeon was using a mixture of 20 gauge, 23 gauge, and 25 gauge surgery.

Twenty gauge surgeries were carried out using self-sealing 20 gauge tunnels as previously described for the Alcon Accurus system and Innovit cutter. ${ }^{7}$ The Innovit cutter has a maximum cut rate of 1800 cuts per minute and has a $0.38 \mathrm{~mm}$ tip to port distance. TSV surgery was carried out using the Alcon Accurus and Constellation 23 gauge systems. The Accurus and Constellations cutters have a maximum cut rate of 2500 and 5000 cuts per minute, respectively, and their tip to port distance is $0.23 \mathrm{~mm}$. A wide-angle noncontact indirect viewing system, with an inbuilt image inverter, was used in all cases.
After core vitrectomy, delamination and removal of all posterior hyaloid face and fibrovascular membrane was carried out. This was carried out primarily with the vitreous cutter alone and intravitreal scissors only if necessary. Twenty gauge horizontal or vertical scissors were used in the 20 gauge group whilst 23 gauge curved horizontal scissors (Grieshaber DSP) were used in the 23 gauge group. In none of the 23 gauge cases was a sclerotomy opened up for 20 gauge instruments. Careful inspection to detect the presence of vitreous schisis was made, and staining of residual vitreous gel using diluted triamcinolone was used routinely in all cases. Any vitreoschisis detected was peeled using the vitreous cutter and forceps as necessary.

Hemostasis was obtained using raised infusion pressure and endodiathermy as needed. The extent of fibrovascular proliferation and vitreoretinal adherence present and requiring peeling/delamination was graded according to disc areas and also classified as by Yorston et al. ${ }^{2}$ Peripheral vitreous was removed, especially around the inner sclerotomy wounds, with deep scleral indentation.

Indirect or endolaser peripheral retinal laser photocoagulation was carried out to the peripheral retina up to the ora serrata in all eyes. A meticulous internal search using endoviewing and indentation with a noncontact wide field viewing system was performed. Retinal breaks were treated with argon laser retinopexy or cryotherapy. Sulfur hexafluoride gas or air were used as postoperative tamponade where needed. Preoperative antivascular endothelial growth factor therapy was not used in any patient.

Retinal breaks observed during vitrectomy were divided into a number of categories by their appearance, causation, and position, and carefully recorded:

- Peripheral sclerotomy-related breaks. Breaks were classified as such if they were retinal dialyses or posterior vitreous base tears within one clock hour of the sclerotomy sites. Retinal breaks in this category were further divided into definite breaks and suspicious lesions. The definition of a definite break included a clearly elevated retinal flap or distinct retinal edge confirmed during retinopexy. Lesions suspicious for breaks were classified if a distinct flap or edge could not be observed but there was some degree of retinal elevation or tufting, especially if associated with localized retinal hemorrhage.

- Other peripheral breaks mainly related to surgically induced extension or creation of a posterior vitreous detachment (PVD). Again these were categorized as definite or suspicious. 
- Pre-existing holes predating the surgery. These were classified as such if seen preoperatively or had signs of chronicity including a pigment ring.

- Posterior retinal breaks, created during membrane dissection or traction from membrane dissection.

Phacovitrectomy was carried out in cases with visually significant cataract obscuring the operative view. Patients were followed up at one day, two weeks, and one, two, four, and six months postoperatively, and then at intervals of 2 to 6 months as needed according to clinical circumstances.

A variety of preoperative and intraoperative characteristics for the patients were recorded, including age, gender, and type and duration of diabetes. The amount of preoperative panretinal photocoagulation administered was graded as equal or more than Early Treatment Diabetic Retinopathy Study (ETDRS) full scatter, less than standard ETDRS full scatter, or no scatter. ${ }^{8}$

\section{Statistical analysis}

The two groups were compared using nonpaired Student $t$-tests for normal continuous variables, and Fisher's Exact test and Chi-squared test as appropriate for categorical data.

\section{Results}

Eighty-five eyes were included in the 20 gauge group and 85 eyes in the 23 gauge group. The groups were well matched in terms of basic demographic variables (Table 1). There

Table I Demographics and other characteristics of groups

\begin{tabular}{|c|c|c|c|}
\hline & 20 gauge control group & 23 gauge group & $P$ value \\
\hline Numbers & 85 eyes (69 patients) & 85 eyes (67 patients) & \\
\hline \multirow[t]{2}{*}{ Age (mean, range, SD) } & $5 I(2 I-8 I)$ years & $50(19-90)$ years & 0.89 \\
\hline & $\mathrm{SD}=15$ & $S D=16$ & \\
\hline \multirow[t]{2}{*}{ Gender } & $38(55 \%)$ male & $35(52 \%)$ male & 0.27 \\
\hline & 31 (45\%) female & 32 (48\%) female & \\
\hline \multirow[t]{2}{*}{ Type of diabetes } & $32(46 \%)$ type I & 27 (40\%) type I & 0.49 \\
\hline & 37 (54\%) type II & 40 (60\%) type II & \\
\hline Duration of diabetes & $17(1-42)$ years & $18(0.5-40)$ years & 0.44 \\
\hline (mean, range, SD) & $\mathrm{SD}=9$ & $S D=8$ & \\
\hline$\% \mathrm{HbA}_{\mathrm{Ic}}$ on admission for surgery & $8.6(5.5 \%-12.3 \%)$ & $8.2(5.6 \%-11.7 \%)$ & 0.39 \\
\hline (mean, range, SD) & $S D=1.5 \%$ & $\mathrm{SD}=1.8 \%$ & \\
\hline Random glucose on admission for surgery & $9.8(2.3-29.6) \mathrm{mmol} / \mathrm{L}$ & $10.6(2.8-29) \mathrm{mmol} / \mathrm{L}$ & 0.24 \\
\hline (mean, range, SD) & $\mathrm{SD}=5.8$ & $\mathrm{SD}=6.0$ & \\
\hline \multirow[t]{3}{*}{ Indication for surgery } & 46 (54\%) eyes vitreous hemorrhage & 44 (52\%) eyes vitreous hemorrhage & 0.48 \\
\hline & $9(10.5 \%)$ macular traction & I3 (I5\%) macular traction & \\
\hline & $30(35 \%)$ both & $28(33 \%)$ both & \\
\hline \multirow[t]{3}{*}{ Amount of preoperative PRP } & $5 \mathrm{I}(60 \%)$ eyes $\geq$ ETDRS full scatter & $54(64 \%)$ eyes $\geq$ ETDRS full scatter & 0.11 \\
\hline & $23(27 \%)$ eyes < ETDRS full scatter & 25 (29\%) eyes < ETDRS full scatter & \\
\hline & II (I3\%) eyes “none” & $6(7 \%)$ eyes "none” & \\
\hline \multirow[t]{2}{*}{ Lens status at time of surgery } & $63(74 \%)$ eyes phakic & $66(78 \%)$ eyes phakic & 0.43 \\
\hline & $22(26 \%)$ eyes pseudophakic & 19 (22\%) pseudophakic & \\
\hline Combined phacoemulsification and IOL & $12(14 \%)$ eyes & $14(16 \%)$ eyes & 0.83 \\
\hline \multirow[t]{4}{*}{ Extent of fibrovascular membrane at vitrectomy } & $17(20 \%)$ eyes $>10 \mathrm{DA}$ & $20(24 \%)$ eyes $>10$ DA & 0.59 \\
\hline & $35(41 \%)$ eyes $2-10$ DA & $37(44 \%)$ eyes $2-10$ DA & \\
\hline & $22(26 \%)$ eyes $<2$ DA & $20(24 \%)$ eyes $<2$ DA & \\
\hline & II (I3\%) eyes none & $8(9 \%)$ eyes none & \\
\hline \multirow[t]{7}{*}{ Categorisation of VR attachments } & PVD: II (I3\%) & PVD: 8 (9\%) & 0.84 \\
\hline & disc attachment only: 12 (I4\%) & disc attachment only: 10 (12\%) & \\
\hline & posterior pole only: 47 (55\%) & posterior pole only: 48 (56\%) & \\
\hline & anterior one quadrant: 9 (I I\%) & anterior one quadrant: 10 (I2\%) & \\
\hline & two quad: 3 (4\%) & two quad: $4(5 \%)$ & \\
\hline & three quad: $2(2 \%)$ & three quad: $2(2 \%)$ & \\
\hline & four quad: I (I\%) & four quad: 2 (2\%) & \\
\hline Gas tamponade used & $27(32 \%)$ eyes & 10 (I2\%) eyes & 0.002 \\
\hline Use of scissors required & $30(35 \%)$ eyes & $5(6 \%)$ eyes & 0.000002 \\
\hline Postoperative rhegmatogenous detachment & I eye & I eye & 1 \\
\hline
\end{tabular}

Note: Suspicious lesions: possible breaks that were suspicious for, but not definite, retinal breaks.

Abbreviations: ETDRS, Early Treatment Diabetic Retinopathy Study; IOL, intraocular lens; SD, standard deviation; PVD, posterior vitreous detachment; VR, vitreoretinal; DA, disc areas; PRP, panretinal photocoagulation. 
were significantly more patients in the 20 gauge group who required the use of scissors to perform delamination. There were also significantly more patients requiring gas tamponade in the 20 gauge group. All other variables assessed between the groups were nonsignificant.

The number of eyes where retinal breaks were observed is shown in Table 2. There was a significant reduction in the incidence of sclerotomy-related breaks and lesions suspicious for breaks, as well as posterior breaks in the 23 gauge group as compared with the 20 gauge group. Two cases in the 20 gauge group had an entry site positioned for retinal dialysis and one case had a tear measuring one and a half clock hours in extent behind the entry site. There were no similar lesions in the 23 gauge group. Scleral buckling was not used in any patient. There was one patient in each group who experienced a retinal detachment postoperatively related in both cases to a posterior retinal break associated with recurrent traction. Postoperative follow-up was for a minimum of six months in all included eyes.

\section{Discussion}

The number of reported retinal breaks found during vitrectomy for PDR has consistently been higher than during vitrectomy for other indications. ${ }^{3}$ Peripheral breaks have been described in diabetic vitrectomy, with rates ranging from $3 \%$ to $22 \%,{ }^{1,2,4,9-12}$ depending on the complexity of the surgery, with approximately $40 \%$ of these related to the sclerotomy entry sites. ${ }^{3}$ Posterior breaks have been described in $10 \%-55 \%$ of cases and again vary according to the complexity of the case series. ${ }^{2,4-11}$ In our 20 gauge cases, we found peripheral retinal breaks in 14\% of all eyes, of which $58 \%$ were sclerotomy site in location and $14 \%$ were posterior retinal breaks. Overall $18.8 \%$ of eyes in our 20 gauge group had new retinal breaks observed during vitrectomy, similar to previous accounts.

We used a tunneled incision 20 gauge technique. Previous case series reporting retinal breaks during 20 gauge diabetic vitrectomy have all used conventional straight incision 20 gauge surgery. Reporting of rates of retinal break formation with similar tunneled techniques has been limited. 7,13,14 Furthermore, rates for diabetic vitrectomy have not been specifically reported, but these publications and our results suggest that the tunneled 20 gauge technique does not increase the rate of break formation compared with conventional 20 gauge surgery.

The rate of retinal break formation during TSV surgery with narrow gauge instruments and cannulated sclerotomies in diabetic vitrectomy has not been systematically described. Tan et al reported a higher rate of retinal break formation during 25 gauge vitrectomy surgery for macular hole and macular pucker relative to previous 20 gauge series, although there was no control group. ${ }^{5}$ However, other authors have found broadly similar rates between narrow gauge and 20 gauge surgery for the same conditions. ${ }^{15,16}$ In a uncontrolled case series, Farouk et al reported that $14.5 \%$ of 200 eyes operated on using 25 gauge TSV for PDR had retinal breaks observed, with the rate rising to $31.5 \%$ in those requiring dissection of membranes. Park et al reported that retinal breaks were observed in $8.6 \%$ of 35 eyes operated on for vitreous hemorrhage associated with PDR using 23 gauge TSV compared with $15.2 \%$ of 66 eyes operated on using 20 gauge surgery. In this latter series, the total difference was not significant and in both these series it is uncertain if the breaks were posterior or peripheral. ${ }^{17,18} \mathrm{We}$ found a lower rate of retinal break formation for both posterior and sclerotomyrelated retinal breaks in our TSV group compared with the

Table 2 Number of retinal breaks in each group

\begin{tabular}{lll}
\hline & $\mathbf{2 0}$ gauge control group & $\mathbf{2 3}$ gauge TSV group \\
\hline Eyes with pre-existing retinal breaks & $2(2 \%)$ & $2(2 \%)$ \\
Eyes with posterior retinal breaks & $12(14 \%)$ & $3(4 \%)$ \\
Eyes with peripheral retinal breaks & $5(6 \%)$ & $3(4 \%)$ \\
located away from sclerotomies & $6(7 \%)$ suspicious lesions & $5(6 \%)$ suspicious lesions \\
Eyes with peripheral sclerotomy & $11(13 \%)$ total & $8(9 \%)$ total \\
related breaks & $7(8 \%)$ & $2(2 \%)$ \\
& $7(8 \%)$ suspicious lesions & $2(2 \%)$ suspicious lesions \\
Total number of eyes with definite & $14(16 \%)$ total & $4(5 \%)$ total \\
peripheral breaks & $12(14 \%)$ & $5(6 \%)$ \\
Total number of eyes with & & 0.72 \\
definite new breaks & $16(18.8 \%)$ & 0.17 \\
& $(8$ eyes had both posterior & $(2$ eyes had both \\
\hline Ab & and peripheral breaks $)$ & 0.123 \\
\hline
\end{tabular}

Abbreviation: TSV, transconjunctival vitrectomy. 
20 gauge group. There are a number of possible explanations for this. TSV utilizes a cannulated entry system which may reduce vitreous base traction during instrument insertion. Indeed, Territto et al demonstrated a lower occurrence of retinal breaks located near the sclerotomy sites using a cannulated entry system in a randomized controlled trial of 77 eyes undergoing vitrectomy for a variety of indications. ${ }^{19}$ This is particularly important in diabetic vitrectomy where instrument exchange is more frequent and scissors are often used. Oyakawa et al previously showed that most peripheral breaks in diabetic vitrectomy are sclerotomy related and commoner on the side of the surgeon's dominant hand. ${ }^{20}$ Ramkissoon et al confirmed this, but only in cases operated on for tractional retinal detachment where more complex dissection was needed. Therefore, cannulated entry systems are of particular relevance in diabetic vitrectomy compared with vitrectomy for macular surgery, where sclerotomy located tears are less common. ${ }^{3}$

Angled scissors commonly used for delamination with 20 gauge surgery cannot be used with cannulated entry systems, and it is likely that there is reduced traction during insertion of the straight or curved instruments used for TSV surgery. Indeed, a change of delamination technique to achieve membrane removal is required with TSV for complex dissections. The introduction of TSV coincided with advancements in vitrectomy cutter design and, in particular, a reduced cutter tip to port distance. The 20 gauge Innovit cutter used has a tip to port distance of $0.38 \mathrm{~mm}$ whilst the corresponding distance for the 23 gauge Accurus and Constellations cutters is $0.23 \mathrm{~mm}$. This, along with the narrower profile of 23 gauge and 25 gauge, allows greater use of cutter delamination and dissection. This technique, along with a technique of bimanual cutter dissection with end gripping forceps to retract tissue whilst cutting, means that scissors are less frequently required to delaminate membranes. Indeed, in our series, scissors were used in 35\% of the 20 gauge cases compared with $6 \%$ of the TSV cases, despite a similar case mix. The 23 gauge Accurus and Constellation cutters also have a higher maximum cut rate of $2500 / 5000$ cuts per minute compared with the 20 gauge Innovit cutter which can go up to 1800 cuts per minute. Higher cut rates result in a lower volume of aspirated tissue per cut at a fixed flow and hence may reduce tissue traction which may, in turn, affect break rate. The greater use of cutter delamination may thus partly also explain the lower rate of posterior and sclerotomy-related breaks we observed with the 23 gauge TSV. Importantly, this also means it is possible that a cannulated 20 gauge system with a new generation cutter would achieve similar results.
The rate of peripheral retinal break formation located away from the sclerotomies, and related mainly to the induction and propagation of a posterior vitreous detachment, was not appreciably different between the two groups. It may be that this study was not large enough to show such a difference but it is perhaps not surprising that there was marked difference because the technique of propagation of a PVD using TSV is the same as that used during 20 gauge surgery.

There are a number of possible confounders in this study which require consideration and these will now be discussed. Firstly, it has been shown that retinal break formation in diabetic vitrectomy is related to the complexity of the case. ${ }^{3,4}$ Sullivan found peripheral retinal breaks in $22 \%$ of tractional retinal detachment cases compared with $13 \%$ of more straightforward vitreous hemorrhage cases. Yorston et al found that the risk of posterior retinal break formation was related to increased vitreoretinal adhesion and tractional retinal detachment at the macula, both of which were related to the complexity of dissection required..$^{2}$ Sclerotomy site breaks were also more common in younger patients. It is thus important to demonstrate that the two groups were matched as closely as possible in our series; we found no significant difference in any of the preoperative values between the two groups, and the groups were well matched in terms of surgical complexity (Table 1). Oshima et al found a lower rate of retinal break formation with 23 gauge surgery for a series of diabetic vitrectomies as compared with 20 gauge surgery, but the 23 gauge group patients had preoperative bevacizumab administered, reducing the complexity of dissection required. ${ }^{10}$ None of our patients in the two groups had bevacizumab either preoperatively or intraoperatively, thus avoiding this confounding factor.

Secondly, it is important to consider the possibility that retinal breaks could have been missed in the TSV group. We think this is unlikely. The surgeries were performed by a single surgeon, and the same retinal inspection regime was used in both groups, with the same wide angle viewing system. As with two other series we also reported possible retinal breaks, which showed the same trend as definite breaks between the two groups of patients. ${ }^{5,21}$ We had two cases of postoperative retinal detachment which were related to recurrent posterior tears which reopened in known breaks that had been treated. Our rate of postoperative retinal detachment was low in both groups at $1 \%$ compared with previous reported rates of $3 \%-18 \% .{ }^{1}$ We had at least six months postoperative follow-up in all patients, and it is unlikely that we missed any postoperative retinal detachment. Careful internal search and treatment of all breaks and lesions which 
could progress postoperatively to retinal breaks is important to minimize postoperative retinal detachment.

Although this study had the strength of being a single surgeon series, being retrospective the findings could potentially be affected by a number of confounders. We examined a number of preoperative factors to ensure the groups were matched, including two measures of vitreoretinal adhesion, known to be the key issue in surgical complexity of PDR cases. The groups were well matched in terms of age and vitreoretinal adhesions. Use of wide angle viewing, and other surgical techniques and equipment other than gauge, were consistent between the two groups. The period when the surgeon was changing from 20 gauge to 23 gauge TSV was specifically avoided to avoid confounding the complexity between the groups. However, it is impossible in a study of this nature to exclude a learning effect by the surgeon completely in terms of reducing retinal break formation.

In conclusion, this study suggests that TSV with cannulated entry systems and new generation cutters results in a lower rate of retinal break formation than with noncannulated 20 gauge surgery.

\section{Disclosure}

The authors report no conflicts of interest in this work.

\section{References}

1. Schrey S, Krepler K, Wedrich A. Incidence of rhegmatogenous retinal detachment after vitrectomy in eyes of diabetic patients. Retina. 2006; 26:149-152.

2. Yorston D, Wickham L, Benson S, Bunce C, Sheard R, Charteris D. Predictive clinical features and outcomes of vitrectomy for proliferative diabetic retinopathy. Br J Ophthalmol. 2008;92:365-368.

3. Ramkissoon YD, Aslam SA, Shah SP, Wong SC, Sullivan PM. Risk of iatrogenic peripheral retinal breaks in 20-G pars plana vitrectomy. Ophthalmology. 2010;117:1825-1830.

4. Carter JB, Michels RG, Glaser BM, DeBustros S. Iatrogenic retinal breaks complicating pars plana vitrectomy. Ophthalmology. 1990;97: 848-853.

5. Tan HS, Mura M, DeSmet MD. Iatrogenic retinal breaks in 25-gauge macular surgery. Am J Ophthalmol. 2009;148:427-429.
6. Heimann H. Primary 25- and 23-gauge vitrectomy in the treatment of rhegmatogenous retinal detachment-advancement of surgical technique or erroneous trend? Klin Monbl Augenheilkd. 2008;225:947-956.

7. Kwok A, Tham C, Lam D, Li M, Chen J. Modified sutureless sclerotomies in pars plana vitrectomy. Am J Ophthalmol. 1999;127:731-733.

8. The Early Treatment Diabetic Retinopathy Study Research Group. Techniques for scatter and local photocoagulation treatment of diabetic retinopathy: Early Treatment Diabetic Retinopathy Study Report No. 3. Int Ophthalmol Clin. 1987;27:254-264.

9. McCleod D. Microsurgical management of neovascularisation secondary to posterior segment ischaemia. Eye. 1991;5:252-259.

10. Oshima Y, Shima C, Wakabayashi T, et al. Microincision vitrectomy surgery and intravitreal bevacizumab as a surgical adjunct to treat diabetic traction retinal detachment. Ophthalmology. 2009;116: 927-938.

11. Schiff WM, Barlie GR, Hwang JC, et al. Diabetic vitrectomy: Influence of lens status upon anatomic and visual outcomes. Ophthalmology. 2007; 114:544-550.

12. Rizzo S, Belting C, Genovesi-Ebert F, Bartolo E. Incidence of retinal detachment after small-incision, sutureless pars plana vitrectomy compared with conventional 20-gauge vitrectomy in macular hole and epiretinal membrane surgery. Retina. 2010;30:1065-1071.

13. Jackson T. Modified sutureless sclerotomies in pars plana vitrectomy. Am J Ophthalmol. 2000;129:116-117.

14. Assi AC, Scott RA, Charteris DG. Reversed self-sealing pars plana sclerotomies. Retina. 2000;20:689-692.

15. Rizzo S, Belting C. Retinal detachment after small-incision, sutureless pars plana vitrectomy: Possible causative agents. Graefes Arch Clin Exp Ophthalmol. 2010;248:1401-1406.

16. Scartozzi R, Bessa AS, Gupta OP, Regillo CD. Intraoperative sclerotomy related retinal breaks for macular surgery, 20- vs 25 -gauge vitrectomy systems. Am J Ophthalmol. 2007;143:155-156.

17. Park DH, Shin JP, Kim SY. Comparison of clinical outcomes between 23 -gauge and 20-gauge vitrectomy in patients with proliferative diabetic retinopathy. Retina. $2010 \mathrm{Jul} 24$. [Epub ahead of print]

18. Farouk MM, Naito T, Sayed KM, et al. Outcomes of 25-gauge vitrectomy for proliferative diabetic retinopathy. Graefes Arch Clin Exp Ophthalmol. 2010 Sep 17. [Epub ahead of print]

19. Territo C, Gieser JP, Wilson CA, Anand R. Influence of the cannulated vitrectomy system on the occurrence of iatrogenic sclerotomy retinal tears. Retina. 1997;17:430-433.

20. Oyakawa RT, Schachat AP, Michels RG, Rice TA. Complications of vitreous surgery for diabetic retinopathy. I. Intraoperative complications. Ophthalmology. 1983;90:517-521.

21. Moore JK, Kitchens JW, Smiddy WE, Mavrofrides EC, Gregorio G. Retinal breaks observed during pars plana vitrectomy. Am J Ophthalmol. 2007;144:32-36.
Clinical Ophthalmology

\section{Publish your work in this journal}

Clinical Ophthalmology is an international, peer-reviewed journal covering all subspecialties within ophthalmology. Key topics include: Optometry; Visual science; Pharmacology and drug therapy in eye diseases; Basic Sciences; Primary and Secondary eye care; Patient Safety and Quality of Care Improvements. This journal is indexed on Submit your manuscript here: http://www.dovepress.com/clinical-ophthalmology-journal

\section{Dovepress}

PubMed Central and CAS, and is the official journal of The Society of Clinical Ophthalmology (SCO). The manuscript management system is completely online and includes a very quick and fair peer-review system, which is all easy to use. Visit http://www.dovepress.com/ testimonials.php to read real quotes from published authors. 